\title{
Oxide reinforced Ni base composite prepared by spark plasma sintering
}

\author{
Guoliang Zhu $u^{1,2, a}$, Shiqi Zhao ${ }^{3}$, Rui Wang ${ }^{1,2}$, Anping Dong ${ }^{1,2}$, Liang Zhang ${ }^{4,5}$, Wenheng $W_{u^{4}, 5}$, Wei Wang ${ }^{1,2}$, Sheng Jiang ${ }^{6}$ \\ and Yilong $\mathrm{Pu}^{6}$ \\ ${ }^{1}$ School of Materials Science and Engineering, Shanghai Jiao Tong University, Shanghai 200240, China \\ ${ }^{2}$ Shanghai Key Laboratory of Advanced High-temperature Materials and Precision Forming, Shanghai 200240, China \\ ${ }^{3}$ School of Mechanical Engineering, Shanghai Jiao Tong University, Shanghai 200240, China \\ ${ }^{4}$ Shanghai Engineering Research Center of 3D Printing Materials, Shanghai 200437, China \\ ${ }^{5}$ Shanghai Research Institute of Materials, Shanghai 200437, China \\ 6 Jiangsu Longda Superalloy Material Co., Ltd, Wuxi 214105, China
}

\begin{abstract}
Y}_{2} \mathrm{O}_{3}$ is a favourable reinforcement for the oxide dispersion strengthened superalloy due to its good high temperature stability, excellent strength and large elastic modulus. In this work, $\mathrm{Y}_{2} \mathrm{O}_{3}$ is introduced into the $\mathrm{K} 4169$ superalloy aiming to improve its high temperature properties. The high quality $\mathrm{Y}_{2} \mathrm{O}_{3}$ and $\mathrm{K} 4169$ powder mixture can be obtained with the addition of the process control agent of stearic acid after high energy ball milling, and the $\mathrm{Y}_{2} \mathrm{O}_{3} / \mathrm{K} 4169$ composite with uniformly dispersed reinforcement of nanoscale $\mathrm{Y}_{2} \mathrm{O}_{3}$ particles are finally synthesized with the ball-milled powders by using spark plasma sintering.
\end{abstract}

\section{Introduction}

Different from the technical route of the optimization of composition and microstructure, the oxide dispersion strengthening (ODS) is an effective method to improve the high temperature performances of materials [1]. Thus, the synthesis of ODS superalloys has attracted wide attention. Yttria $\left(\mathrm{Y}_{2} \mathrm{O}_{3}\right)$ is a common reinforcement for ODS superalloy due to its high thermal stability, favourable strength and elastic moudulus [2]. Benjamin [3] has prepared the $\mathrm{Y}_{2} \mathrm{O}_{3}$ reinforced superalloy by using mechanical alloying in 1970s. Later, a few ODS superalloys have been invented, including MA754 and PM3000, in which the concentration of $\mathrm{Y}_{2} \mathrm{O}_{3}$ is $0.6 \mathrm{wt} . \%$ and $0.9 \mathrm{wt} . \% \quad \mathrm{Y}_{2} \mathrm{O}_{3}$ respectively. The superalloys strengthened by $\mathrm{Y}_{2} \mathrm{O}_{3}$ have been widely applied in aero engines. Moreover, $\mathrm{Y}_{2} \mathrm{O}_{3}$ also can react with the elements in matrix or other added elements to form new reinforcing phases, resulting in better strengthening effect. The $\mathrm{Y}_{3} \mathrm{Al}_{5} \mathrm{O}_{12}, \mathrm{YAlO}_{3}$ and $\mathrm{Y}_{4} \mathrm{Al}_{2} \mathrm{O}_{9}$ phases are formed in the MA6000 alloy due to the reactions between $\mathrm{Y}_{2} \mathrm{O}_{3}$ and $\mathrm{Al}$ during the mechanical alloying [4]. the addition of $\mathrm{Hf}$ in PM1000 ODS superalloy leads to the formation of $\mathrm{Y}_{2} \mathrm{Hf}_{2} \mathrm{O}_{7}$ which has better interface characteristics with the matrix compared to $\mathrm{Y}_{2} \mathrm{O}_{3}[5]$.

$\mathrm{K} 4169$ alloy is a commercial superalloy which has similar composition and microstructure with IN718C alloy. The high temperature strength of K4169 is not satisfactory though it has excellent comprehensive properties when the service temperature is lower than $650^{\circ} \mathrm{C}[6-8]$.

In this work, $\mathrm{Y}_{2} \mathrm{O}_{3} / \mathrm{K} 4169$ composite is prepared by using high energy ball milling (HEBM) and spark plasma

a Corresponding author: glzhu@sjtu.edu.cn sintering (SPS) to improve the high temperature strength of matrix K4169 superalloy. The microstructures of the ball-milled $\mathrm{Y}_{2} \mathrm{O}_{3}$ and $\mathrm{K} 4169$ powders as well as the microstructure of $\mathrm{Y}_{2} \mathrm{O}_{3} / \mathrm{K} 4169$ composite after SPS are studied.

\section{Materials and method}

High-purity $\mathrm{Y}_{2} \mathrm{O}_{3}$ powders and $\mathrm{K} 4169$ powders are used as raw materials. Spherical K4169 powders $(45 \mu \mathrm{m})$ and nanoscale $\mathrm{Y}_{2} \mathrm{O}_{3}$ powders $(50 \mathrm{~nm})$ are added to a ball milling jar. The weight ratio of $\mathrm{Y}_{2} \mathrm{O}_{3}$ in the powder mixture is $10 \mathrm{wt} . \%$, and $0.5 \mathrm{wt} . \%$ of stearic acid is used as process control agent for HEBM. The weight ratio of steel balls to the powder mixture is 10:1. The HEBM is conducted with a rotating speed of $300 \mathrm{rmp}$, and the ball milling time is $12 \mathrm{~h}$. After HEBM, the passivation of powders is conducted under $0.2 \mathrm{~atm}$ for $30 \mathrm{~min}$ in an argon glove box to avoid self-burning due to the high activity of ball-milled powders. Then the ball-milled powder mixture is sintered in SPS apparatus at $1050{ }^{\circ} \mathrm{C}$ under the pressure of $50 \mathrm{MPa}$ for $5 \mathrm{~min}$.

The microstructure of ball-milled powders before SPS and the $\mathrm{Y}_{2} \mathrm{O}_{3} / \mathrm{K} 4169$ composite after SPS are investigated by using scanning electron microscope (JSM7600F). The phases of the ball-milled powders before SPS and the $\mathrm{Y}_{2} \mathrm{O}_{3} / \mathrm{K} 4169$ composite after SPS are analysed by X-ray diffractometer (Bruker AXS D8), $\mathrm{Cu}$ target and a scanning speed of $0.2 \% \mathrm{~s}$ are employed for XRD tests.

\section{Results and discussion}


Figure 1 shows the SEM images of the ball-milled powders. The size of the K4169 powders is greatly decreased from $45 \mu \mathrm{m}$ to $20 \mu \mathrm{m}$. No obviously scattered $\mathrm{Y}_{2} \mathrm{O}_{3}$ particles are found in the ball-milled powders, indicating that the nanoscale $\mathrm{Y}_{2} \mathrm{O}_{3}$ powder and microscale K4169 powders are homogeneously mixed after HEBM.

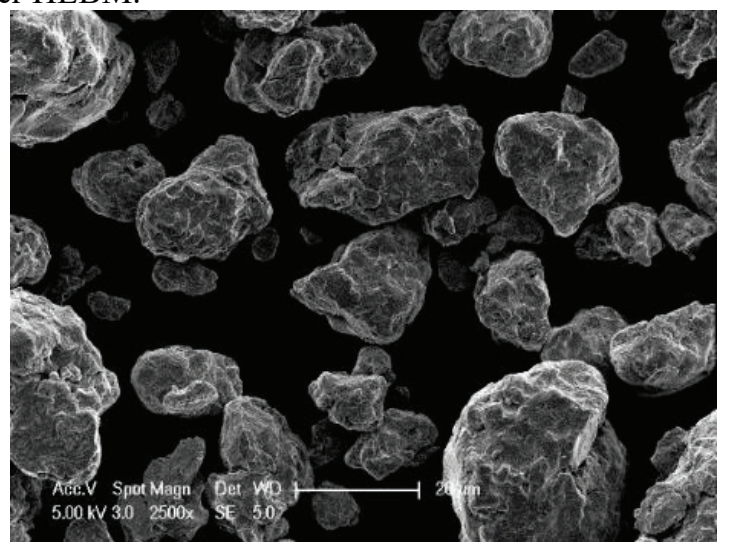

Figure 1. SEM morphology of the ball-milled $\mathrm{Y}_{2} \mathrm{O}_{3}$ and $\mathrm{K} 4169$ powders after HEBM.
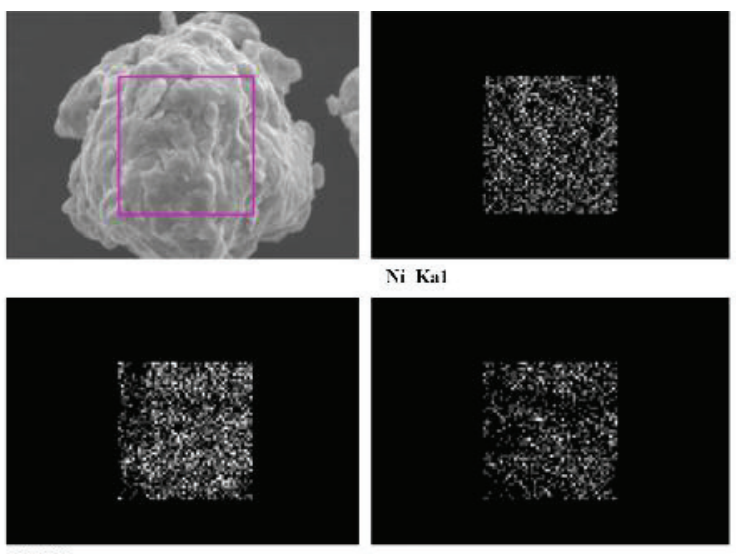

Ni Ka1

Y Kal

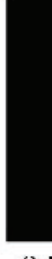

o kin

Figure 2. The distribution of elements in the ball-milled $\mathrm{Y}_{2} \mathrm{O}$ and K4169 powders after HEBM.

The energy dispersive spectrometry results of a ballmilled powder, as shown in Figure 2. Both oxygen and yttrium are uniformly distributed in the ball-milled powder, without obvious aggregation. The result confirms that high quality $\mathrm{Y}_{2} \mathrm{O}_{3}$ and $\mathrm{K} 4169$ powder mixture can be prepared after HEBM for $12 \mathrm{~h}$ with the help of process control agent of stearic acid.

Figure 3 shows the XRD pattern of the ball-milled $\mathrm{Y}_{2} \mathrm{O}_{3}$ and $\mathrm{K} 4169$ powders after HEBM. The characteristic diffraction peaks of $\mathrm{Ni}$ and $\mathrm{Y}_{2} \mathrm{O}_{3}$ are clear and sharp. Moreover, no other characteristic diffraction peak is found in Figure 3, indicating that no impurity is formed during the HEBM.

The XRD pattern of $\mathrm{Y}_{2} \mathrm{O}_{3} / \mathrm{K} 4169$ composite after SPS is shown in Figure 4. The characteristic diffraction peaks of $\gamma$ phase and $\mathrm{Y}_{2} \mathrm{O}_{3}$ are observed, indicating that the $\mathrm{Y}_{2} \mathrm{O}_{3}$ was thermal stable during the SPS. Considering that the standard heat treatment is not carried out for $\mathrm{Y}_{2} \mathrm{O}_{3} / \mathrm{K} 4169$ composite after SPS, it is reasonable that the characteristic diffraction peaks of $\gamma^{\prime}$ and $\gamma^{\prime \prime}$ phases are not found in the XRD pattern.

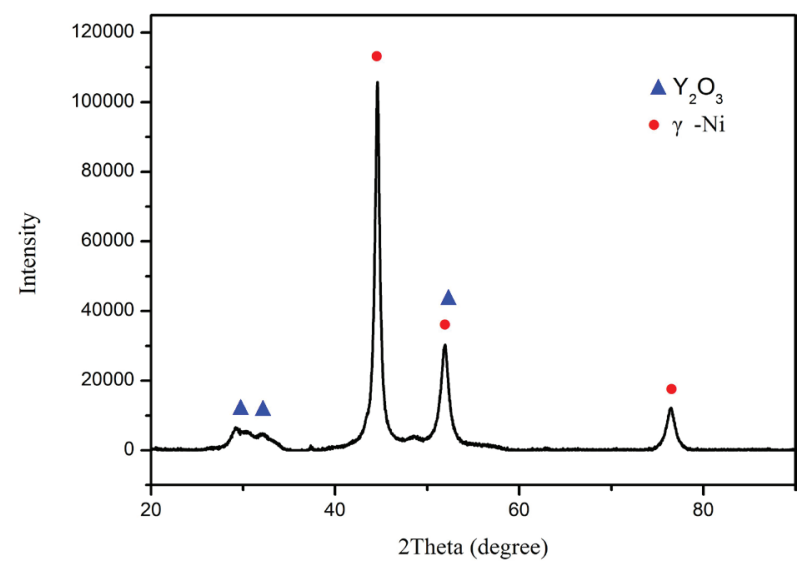

Figure 3. XRD pattern of the ball-milled $\mathrm{Y}_{2} \mathrm{O}_{3}$ and $\mathrm{K} 4169$ powders after HEBM.

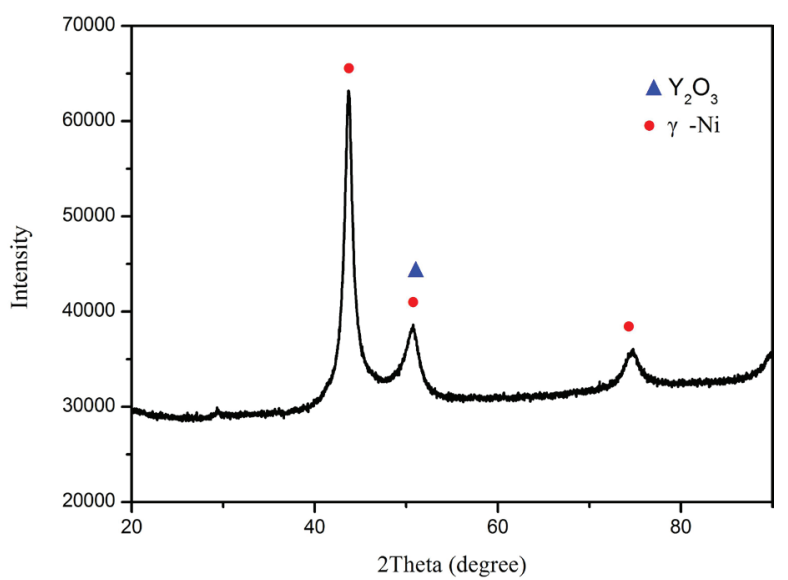

Figure 4. XRD pattern of $\mathrm{Y}_{2} \mathrm{O}_{3} / \mathrm{K} 4169$ composite after SPS.

It is believed that the nanoscale $\mathrm{Y}_{2} \mathrm{O}_{3}$ could enhance the material strength through the dislocation pinning mechanism. With the coarsening of $\gamma^{\prime}$ and $\gamma^{\prime \prime}$ phases during long time service of $\mathrm{Y}_{2} \mathrm{O}_{3} / \mathrm{K} 4169$ composite, the strengthening effect from $\gamma^{\prime}$ and $\gamma^{\prime \prime}$ is greatly decreased, but the $\mathrm{Y}_{2} \mathrm{O}_{3}$ could still work as reinforcement to strengthen the matrix, due to its high thermal stability. In the future, the deformation behavior and the microstructure evolution after heat treatment will be investigated to further optimize the microstructure of $\mathrm{Y}_{2} \mathrm{O}_{3} / \mathrm{K} 4169$ composite, aim to improve the hightemperature performance of $\mathrm{Y}_{2} \mathrm{O}_{3} / \mathrm{K} 4169$ composite.

\section{Conclusion}

The high quality $\mathrm{Y}_{2} \mathrm{O}_{3}$ and $\mathrm{K} 4169$ powder mixture can be obtained by HEBM which is performed with a rotational speed of $300 \mathrm{rmp}$ for $12 \mathrm{~h}$ under argon protection, and the $\mathrm{Y}_{2} \mathrm{O}_{3} / \mathrm{K} 4169$ composite with uniformly distributed nanoscale $\mathrm{Y}_{2} \mathrm{O}_{3}$ particles is prepared by SPS of the ballmilled powders. It is believed that the nanoscale $\mathrm{Y}_{2} \mathrm{O}_{3}$ in $\mathrm{Y}_{2} \mathrm{O}_{3} / \mathrm{K} 4169$ composite could greatly enhance the material strength through the dislocation pinning mechanism during long time service due to its high thermal stability. The optimization of the microstructure of $\mathrm{Y}_{2} \mathrm{O}_{3} / \mathrm{K} 4169$ composite will be further investigated in the next research work.

\section{Acknowledgement}


This work was financially supported by the Joint fund of the Ministry of Education of China under Project No. 6141A02022210, the National Natural Science Foundation of China under Project No. 51704195, the Industry-University-Research Cooperation Annual Plan of Shanghai under Project No. CXY-2016-004, the National Industrial Basis Improvement Project under Project No. TC160A310-12-1 and Special fund for research and development platform of Shanghai Science and Technology Commission under Project No. 16DZ2260605.

\section{References}

1. I. Hilger, M. Tegel, M.J. Gorley, et al. The structural changes of $\mathrm{Y}_{2} \mathrm{O}_{3}$ in ferritic ODS alloys during milling. J. Nucl. Mater., 447, 242-247 (2014)

2. T. Liu, H. Shen, C. Wang, et al. Structure evolution of $\mathrm{Y}_{2} \mathrm{O}_{3}$ nanoparticle/Fe composite during mechanical milling and annealing. Prog. Nat. Sci.: Mater. Int., 23, 434-439 (2013)

3. J.S. Benjamin. Dispersion strengthened superalloys by mechanical alloying. Metall. Tran., 1, 2943-2951 (1970)

4. G.B. Schaffer, M.H. Loretto, R.E. Smallman, et al. The nature of the dispersoids in INCONEL alloy M A6000. J. Mat. Sci., 24, 3261-3266 (1989)

5. N. Oono, Q.X. Tang, S. Ukai. Oxide particle refinement in Ni-based ODS alloy. Mat. Sci. Eng. A, 649, 250-253 (2016)

6. R. Cozar, A. Pineau. Morphology of $\gamma^{\prime}$ and $\gamma^{\prime \prime}$ precipitates and thermal stability of inconel 718 type alloys. Metall. Trans., 4, 47-59 (1973)

7. E. Guo, F. Xu, E.A. Loria. Improving thermal stability of alloy 718 via small modifications in composition. Superalloy 718- Metallurgy and Applications, 567-576 (1989)

8. X. Liu, J. Dong, B. Tang, et al. Investigation of the abnormal effects of phosphorus on mechanical properties of INCONEL718 superalloy. Mat. Sci. Eng. A, 270, 190-196 (1999) 